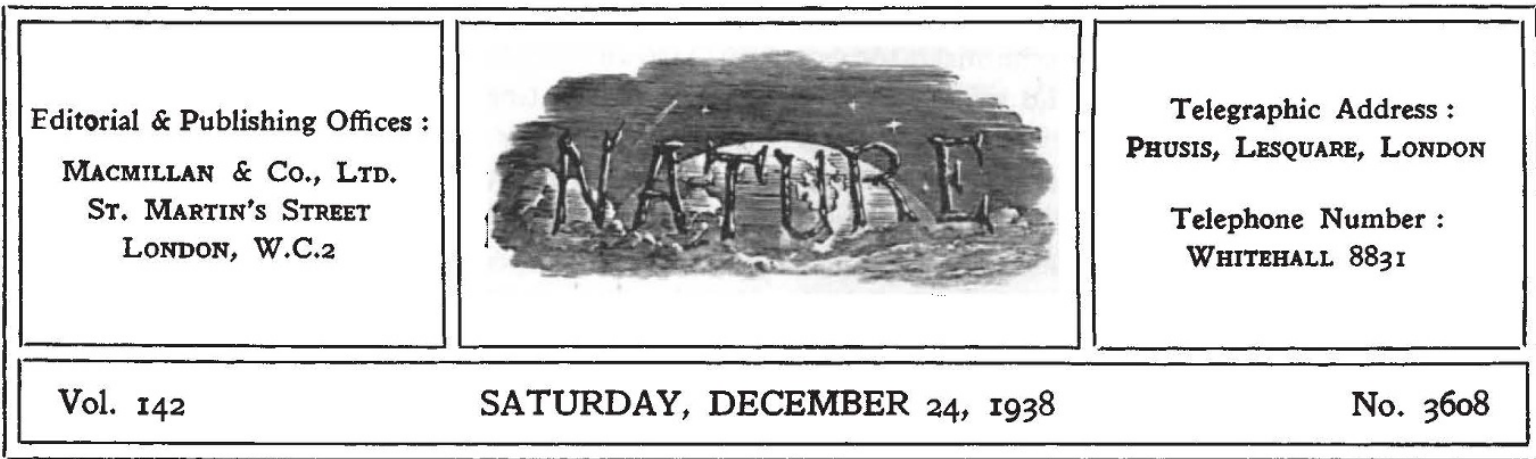

\title{
An African Bureau
}

$\mathrm{T}^{\mathrm{n}}$ HE African Survey, for which Lord Hailey has been responsible, derives no small share of its value from the comprehensive way in which it brings together in readily accessible form information that previously was extremely scattered and difficult to collect. On this ground alone, apart from its critical suggestions, the Survey is of immense value to all those concerned with African problems whether in the administrative or economic sphere, in scientific work or in philanthropic or missionary enterprise.

The very magnitude of the survey made, however, with its masses of data, emphasizes the point so strongly stressed in the Survey, that, in contrast with India, where information on such subjects is usually readily accessible, it is very difficult to obtain information on matters which are essential to an understanding of conditions in Africa. This difficulty is experienced fairly widely, though to an extent differing in various fields, and being perhaps more conspicuous in regard to political, economic or social developments than in the scientific field. Here, of course, the bulletins issued by the Imperial Agricultural Bureaux and the periodicals and reports issued by the medical and other research institutions in Great Britain, circulate full information on the progress of scientific investigations in a wide field.

Even these publications, however, do not usually distinguish the matters which specially concern Africa and are scarcely to be found collected in any one institution. This difficulty is much greater in the other fields. The Institut Colonial International issues from Brussels publications which are a valuable source for the documentation of the legislative and similar proceedings of colonial
Governments, and its periodical sessions have yielded a useful series of discussions on different problems in administration. There are also a number of journals devoted exclusively to social, linguistic and similar studies of Africa, such as Africa, the journal of the Royal African Society, or Congo and certain journals are published locally in the African colonies. In addition to this periodical literature, there is a growing mass of general literature on Africa as well as of studies of special problems. Those sources of information are all, however, very scattered, and sometimes, as in certain French and Portuguese territories, are difficult of access. The compilation of a comprehensive bibliography, let alone the examination of source material, on many African problems is apt to be extremely laborious and expensive.

None of the available sources of information on Africa is open to the public. All are circumscribed by other purposes and in none of them are African problems considered as the major interest. Moreover, the difficulty of obtaining material is frequently accompanied by difficulty in judging its real bearing or value. Where, as in Europe or the Dominions, public measures are fully discussed in the Press or in a representative legislature, the observer is able to consider facts or statistics in relation to the policy which gives them their significance. This advantage is seldom enjoyed by observers of African colonial administrations, where policy is frequently decided in proceedings which are not made available to the public.

As regards the applied sciences, as already indicated, a wealth of material is available to the student in the scientific periodicals which the various abstract periodicals of the Imperial 
Bureaux assist in rendering available. Here the difficulty lies rather in providing means by which the non-technical inquirer or the administrator can inform himself of the value of the work which is being discussed and its bearing on the practical problems with which he may have to deal. The success of a modern Colonial administration depends largely on the use which it makes of its technical departments, and accordingly any agency which keeps the administrator in touch with the contributions made by science to the solution of his problems is of value.

These are the reasons which led to the second main recommendation of the Survey-the provision of some effective means for making knowledge of Africa more accessible, not only to the public but also to those interested in the special study of African questions. To this end is advised the institution of an African Bureau, preferably situated in London, and designed on lines which would make it not only a source of information on practically every aspect of activity in Africa, but also a convenient body to maintain close contact with institutions and voluntary organizations in Great Britain and other countries interested in African development. The Bureau should be constituted so as to be capable of providing guidance to those who seek to pursue a special study in any subject of interest in Africa, or of placing them in touch with those who are competent to do so.

The scheme contemplates the appointment of a director who should himself have some experience of the requirements of social or scientific investigation. He should have as assistants, three specialists, acquainted with African conditions, and with knowledge, respectively, of scientific, economic and social (including administrative) subjects. They would publish periodically a survey of contributions to the knowledge of Africa and of events which affect workers in any branch of study. Their main contribution would not be the result of any original study ; they would be dealing with information, much of which would be recorded in some form or another elsewhere.

In regard to the assembling of material, a nucleus already exists in the offices of the African Research Survey, consisting of the more important Government reports and a library of important books on Africa. This material, as well as a large number of leaflets and memoranda specially prepared for the Survey, is already classified and filed under appropriate headings, and some of it would be difficult to obtain elsewhere.
Experience must decide how far the Bureau should proceed in assembling a library of literature on African subjects. Particularly in regard to the earlier publications, it may prove unnecessary to duplicate in the library of the Bureau some of the material on Africa already to be found in the libraries of the Colonial Office, South Africa House, the Royal African Society and the Royal Empire Society. It would indeed be of advantage to avoid amassing material unlikely to be used by those concerned with the present-day development of Africa. Equally, of course, this material will frequently require supplementing on the foreign side, and it will also be essential, in regard to scientific and technical subjects, that the staff of the Bureau should acquire a working knowledge of the information available in the libraries of the different scientific institutions and of the additions which scientific research is making to it.

On this side of the work of the Bureau, an organization such as the Association of Special Libraries and Information Bureaux may well be able to render signal service in the initial stages. Some of the most important aspects of the work of the Bureau will, however, be the establishment of contacts, particularly with such institutions in Great Britain as the International Institute of African Languages and Culture or the Royal African Society. It may even be possible to establish a common library and to group these three particular institutions in the same building. Overseas contacts, however, are equally important, whether with the "Bureau Internationale de Renseignments" of the Institut Colonial International of Brussels or with official and non-official circles responsible for developments in the Union of South Africa, for example.

The Survey estimates that the proposal for an African Bureau involves an initial expenditure of about $£ 10,000$ a year, including the renting of suitable accommodation, though this expenditure would probably increase as the work developed. While it is hoped that the Bureau would receive full support from the British Government, the desirability of control by a non-official body which would be in a position to seek assistance also from Colonial Governments and from other sources is emphasized. The scheme visualizes control by a managing committee, including representatives nominated by the Colonial Office, the Union of South Africa and Southern Rhodesia, the International Institute of African Languages and the Royal African Society. If the proposal is adopted, 
this committee might well be extended, by co-option or otherwise, to include representatives from different branches of science, the International Missionary Council and the like.

The organization of a clearing-house of information on these lines should directly assist the application on a much greater scale of existing scientific knowledge in the service of African needs and the solution of African problems at what the Survey describes as the most critical and formative period of African history. Equally it should stimulate further research, particularly the more comprehensive study of the factors determining the nature of its social development and a more scientific approach to the problems of health and material well-being to which the physical characteristics of the natives of Africa have given rise.

On both these grounds the project claims the interest and support of all scientific workers, and particularly at a time when constructive development on such lines may well hold the key to the solution of the more threatening aspect of the problem of Colonies themselves.

\section{The Science of Slang}

A Dictionary of Slang and Unconventional English :

Slang, including the Language of the Underworld, Colloquialisms and Catch-phrases, Solecisms and Catachreses, Nicknames, Vulgarisms, and such Americanisms as have been naturalized. By Eric Partridge. Second edition, revised and enlarged. Pp. xviii + 1051. (London: George Routledge and Sons, Ltd., 1938.) 42s. net.

A DICTIONARY of slang may, at first sight, A seem to have no special message for readers of NATURE, but it is impossible to turn over the pages of Mr. Partridge's monumental work without realizing how many important and perplexing problems, philological, psychological and social, are raised in the pages of this dictionary. The book provides data that will be eagerly seized on by the students of many sciences.

What is slang? We have somewhere to set a term to definition, and it may be assumed that everyone knows what is meant by standard English. Making this rather large assumption, we know also that there are deviations from the standard which are not to be classed as dialectdeviations which consist in substitutes, generally undignified, sometimes humorous, and sometimes coarse, "for those modes of expression which are employed by persons who value themselves on propriety of speech". Such substitutes are, for the most part, slang, and the reasons for their introduction make as difficult a scientific problem as do the philological problems involved in the derivation of the words themselves.

Over and above this, there are jargons developed by groups which desire their speech to remain cryptic-such jargons have been invented by schoolboys, by vagrants, by professional thieves, and not infrequently have in their make-up a considerable element of humour. The desire to use words or phrases which, without being cryptic or necessarily more exact in technical meaning, shall be different (and usually humorously different) from those usually employed, gives rise to the slang of certain trades and professions. A massive contribution to Mr. Partridge's dictionary accrues from terms which, in some instances originally standard English, have, for reasons not always apparent, become coarsened and colloquial and are certainly not used to-day by that class which prides itself on propriety and refinement in speech. Many such expressions possess a Rabelaisian humour and outspokenness which is some. thing of a saving grace ; many are frankly coarse $a b$ initio and have never appeared in standard English. In dealing with this last-named class of unpleasant terms, Mr. Partridge is at pains to assure us that his method has been to handle them "as briefly, as astringently, as aseptically as was consistent with clarity and adequacy". $\mathrm{He}$ is, in short, in this matter, a consistent disciple of his great predecessor, Captain Grose. None of these categories has been neglected by Mr. Partridge. Johnson could say, speaking of the technical terms of various arts and crafts :

"I could not visit caverns to learn the miner's language, nor take a voyage to perfect my skill in the dialect of navigation, nor visit the warehouses of merchants and shops of artificers to gain the names of wares, tools and operations, of which no mention is found in books; what favourable accident or easy inquiry brought within my reach, has not been neglected; but it had been a hope. less labour to glean up words by courting living information, and contesting with the sullenness of one, and the roughness of another." 